\title{
Histological evaluation of five suture materials in the telson ligament of the American horseshoe crab (Limulus polyphemus)
}

Ami E Krasner ${ }^{1}$, Amy Hancock-Ronemus ${ }^{2}$, Larry S Christian ${ }^{3}$, Emily H Griffith ${ }^{4}$, Gregory A Lewbart ${ }^{\text {Corresp., } 5}$, Jerry M Law $^{6}$

1 Hollin Hall Animal Hospital, Alexandria, Virginia, United States

2 University of Massachusetts at Dartmouth, North Dartmouth, Massachusetts, United States

3 Veterinary Services, North Carolina Museum of Natural Sciences, Raleigh, NC, United States

4 Department of Statistics, North Carolina State University, Raleigh, NC, United States

5 Department of Clinical Sciences, North Carolina State University, Raleigh, North Carolina, United States

6 Department of Population Health and Pathobiology, North Carolina State University, Raleigh, NC, United States

Corresponding Author: Gregory A Lewbart

Email address: greg_lewbart@ncsu.edu

An ideal suture material supports healing, minimizes inflammation, and decreases the likelihood of secondary infection. While there are published recommendations for suture materials in some invertebrates, there are no published recommendations for Limulus polyphemus or any chelicerate. This study evaluates the histological reaction of horseshoe crabs to five commonly used suture materials: monofilament nylon, silk, poliglecaprone, polydioxanone, and polyglycolic acid. None of the materials were superior with regards to holding nor was there any dehiscence. Nylon evoked the least amount of tissue reaction. This work also provides a histopathological description of the soft membrane at the hinge area between the opisthosoma and telson (telson ligament) and comments on euthanasia with intracardiac eugenol. 
1 Title: Histological evaluation of five suture materials in the telson ligament of the American horseshoe

2 crab (Limulus polyphemus).

3

4

5 Authors: Ami E. Krasner, ${ }^{1}$ Amy Hancock-Ronemus, ${ }^{2}$ Larry S. Christian, ${ }^{3}$ Emily

6 H. Griffith, ${ }^{4}$ Gregory A. Lewbart, ${ }^{5}$ and Jerry M. Law. ${ }^{6}$

7 Institutional affiliations: ${ }^{1}$ Hollin Hall Animal Hospital, Alexandria, Virginia; ${ }^{2}$ University of

8 Massachusetts Dartmouth, North Dartmouth, Massachusetts; ${ }^{3}$ Veterinary Services, North Carolina

9 Museum of Natural Sciences, Raleigh, North Carolina; ${ }^{4}$ Department of Statistics, North Carolina State

10 University, Raleigh, North Carolina; ${ }^{5}$ Department of Clinical Sciences, North Carolina State University,

11 Raleigh, North Carolina; ${ }^{6}$ Department of Population Health and Pathobiology, North Carolina State

12 University, Raleigh, North Carolina

14 Corresponding author: Gregory A. Lewbart; greg_lewbart@ncsu.edu

Running head: Suture evaluation in horseshoe crabs

17 
28 Abstract: An ideal suture material supports healing, minimizes inflammation, and decreases the

29 likelihood of secondary infection. While there are published recommendations for suture materials in

30 some invertebrates, there are no published recommendations for Limulus polyphemus or any chelicerate.

31 This study evaluates the histological reaction of horseshoe crabs to five commonly used suture materials:

32 monofilament nylon, silk, poliglecaprone, polydioxanone, and polyglycolic acid. None of the materials

33 were superior with regards to holding nor was there any dehiscence. Nylon evoked the least amount of

34 tissue reaction. This work also provides a histopathological description of the soft membrane at the hinge

35 area between the opisthosoma and telson (telson ligament) and comments on euthanasia with intracardiac

36 eugenol.

37

38

39

40

41

42

43

44

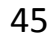

46

47

Peer) reviewing PDF | (2018:10:32319:1:2:NEW 23 Apr 2019) 


\section{Introduction}

50

51

52

53

54

55

56

57

58

59

60

61

62

63

64

65

66

67

68

69

70

71

Over the last few decades, there has been increasing awareness of invertebrate species in veterinary medicine. Species-specific medical practices allow clinicians to provide the optimal quality of care for each patient. There are limited published research or review articles regarding best practices for caring for the American Horseshoe crab, Limulus polyphemus, despite this marine invertebrate's common use as a laboratory animal and in public aquaria (Smith et al., 2002; Leibovitz and Lewbart, 2004; Smith and Berkson, 2005; Gore et al., 2006; Smith, 2012; Tuxbury et al., 2014).

Horseshoe crabs are used as research models due to the ability to extrapolate their anatomy and physiology to other species, their ease of adaptability as laboratory animals, and their unique blood circulatory features. Limulus's large, compound eyes have been successful models in the understanding of mammalian vision (Lui and Passaglia, 2009). The hemolymph of horseshoe crabs is used in the pharmaceutical industry worldwide to reliably ensure the safety of biologicals, pharmaceutical drugs, and medical devices. Horseshoe crab hemolymph is harvested from over 500,000 animals annually to produce Limulus amebocyte lysate (LAL), a substance that detects harmful levels of endotoxin in human and veterinary medical products (Grant, 2001; Walls and Berkson, 2003; Novitsky, 2001; Novitsky, 2009; Anderson et al., 2013). LAL has other important applications in food safety, disease diagnosis in the clinical laboratory, in ecological monitoring of environmental systems, and in controlling endotoxin in the equipment and procedures to produce pharmaceuticals (Novitsky, 2001). Chitin from the horseshoe crab's exoskeleton is considered to have healing properties and has been used as an absorbable suture material and for wound dressings for burn victims (Tanacredi, 2001; Smith and Berkson, 2005).

Although horseshoe crabs have persisted for more than 200 million years, the conservation status of free ranging L. polyphemus has been evaluated over the last two decades to help ensure this keystone species' continued survival (Eldridge, 2001; Anderson et al., 2013; Smith et al., 2017). The latest 
72 assessment suggests that L. polyphemus are vulnerable to local extinction based on subregional

73 differences in environmental conditions, threats, and management (Smith et al., 2017). The harvest

74 process for LAL collection may be contributing to local population decline through animal mortality and

75 from decreased female fitness in those returned to the wild during the spawning season (Hurton et al.,

76 2009; Anderson et al., 2013). Currently, the largest harvests of L. polyphemus are in the American eel

77 (Anguilla rostrate), conch (Busycon spp.), and whelk commercial fishing industries where they are the

78 most effective bait source (Eagle, 2001; ASFMC, 2009; Anderson et al., 2013; Smith et al., 2017).

79 Overharvesting of horseshoe crabs in the fishing industry may also have deleterious effects on migrating

80 shorebirds who rely on horseshoe crab eggs to help fuel their voyage (Eagle, 2001). Changing shoreline

81 dynamics with human development has decreased habitat availability for horseshoe crab breeding

82 grounds and can limit population growth (Hata and Berkson, 2003; Smith et al., 2017). Other factors

83 including climate change, water quality and pollution events, and bycatch are also considered threats to $L$.

84 polyphemus population status (Smith et al., 2017).

Conservation efforts may help protect horseshoe crabs from population decline. There are stricter, although likely inadequate (Smith et al., 2017), regulations on harvesting by the bait fishery and biomedical bleeding industries (ASMFC, 2006; ASMFC, 2010b), considerations for alternative baits and more efficient use of baits, and efforts to implement a new endotoxin test to replace or supplement the LAL test or to make the LAL test more sustainable (Krisfalusi-Gannon et al., 2018). While horseshoe crab populations have stabilized in the Delaware Bay region and increased in abundance in parts of the Southeast, the Northeast region continues to see a decrease in abundance and the stock status is currently undergoing a benchmark assessment (ASFMC, 2015; ASFMC, 2017; Smith et al., 2017). The International Union for Conservation of Nature (IUCN) predicts a 30\% decline over the next 40 years 94 (Smith et al., 2017; Krisfalusi-Gannon et al., 2018). 
97 etiologies causing health problems include algae, fungi, colonial and filamentous cyanobacteria, Gram-

98 negative bacteria, and parasites. Commonly seen green algal infections can affect the carapace and

99 accessory structures including the dorsal arthrodial membrane (over the heart) and telson ligament (the

100 membrane at the base of the telson connecting the opisthosoma to the telson) (Smith and Berkson, 2005;

101 Braverman et al., 2012). A significant non-infectious disease of captive horseshoe crabs is

102 panhypoproteinemia, but traumatic injuries, water quality problems, and molting problems are also seen.

103 Traumatic injuries sustained during collection, transport, or overcrowding in captivity can cause puncture

104 wounds, crushing of the exoskeleton, and fractures of the carapace (Smith and Berkson, 2005).

Wound repair and immune defense in the horseshoe crab have been well documented as the

migration of granular hemocytes (amebocytes) from the hemolymph to the area of trauma or infection and

subsequent clot formation (Bursey, 1977; Clare et al., 1990; Iwanaga, 2002; Iwanaga and Lee, 2005).

Horseshoe crabs have innate immune systems where hemocytes respond to pathogens by the exocytosis

of large and small granules that contain antimicrobial and coagulation proteins, forming a clot or

“coagulum" (Iwanaga, 2002). Hemocytes are large, round to irregularly shaped cells (7 to $11 \mu \mathrm{m}$ in

diameter) with abundant cytoplasm that contains coarse, bright red secretory granules and a single, dark

and basophilic nucleus (Tuxbury et al., 2014). Once activated, hemocytes can become elongated with the

113 cytoplasmic granules no longer apparent and the nucleus can have a distinct halo (Bursey, 1977). The

114 hemolymph of horseshoe crabs and granules in hemocytes both contain a variety of highly efficient

115 defense molecules (Iwanaga, 2002; Iwanaga and Lee, 2005). The defense systems include hemolymph

116 coagulation and coagulum formation, melanization, complement activation, cell agglutination,

117 antimicrobial action, reactive oxygen species formation, and phagocytic action (Iwanaga, 2002). 
122 rates (Tuxbury et al., 2014). As standards of care for aquatic invertebrate medicine continue to advance,

123 appropriate diagnostic testing and treatments may increase longevity among captive horseshoe crabs.

124 Although harvest for the marine life aquarium trade, scientific collection, and educational use is smaller

125 than the bait fishery and biomedical industries (Smith et al., 2017), veterinary management of captive

126 horseshoe crabs may mitigate the need to replace research or public display animals and could increase

127 the return rate and fitness of the biotechnology population to the wild.

128 When surgery is indicated, an ideal suture material supports healing by preventing suture

129 dehiscence, minimizing inflammation, and decreasing the likelihood of secondary infection (Fossum,

130 2007). There are published recommendations for suture materials in other invertebrates (Anderson et al.,

131 2010; Salgado et al., 2014), but there are no published recommendations for L. polyphemus or any other

132 chelicerate. While surgical epoxy may sufficiently close a wound in the well-mineralized carapace,

133 sutures may be more appropriate for closure of a wound caused by traumatic injury, biopsy for diagnosis

134 of infectious disease, or surgery affecting less mineralized chitinous or non-chitinous tissues (Nolan and

135 Smith, 2009). Making a surgical window to assess the internal structures may be achieved from less

136 mineralized chitinous areas (Nolan and Smith, 2009). Knowledge of the most appropriate suture materials

137 for horseshoe crabs may also be extrapolated for veterinary use in other chelicerate arthropods. This study

138 evaluates the histological reaction of L. polyphemus to five suture materials commonly used in veterinary

139 medicine: monofilament nylon, silk, poliglecaprone, polydioxanone, and polyglycolic acid. This paper

140 also comments on a euthanasia method for horseshoe crabs. Although histological descriptions of many

141 clinically relevant organs have been described (Packard, 1880a and 1880b; Fahrenbach, 1999; Nolan and

142 Smith, 2009), this work provides a further detailed microscopic description of the telson ligament.

\section{Materials and Methods}

Thirty adult L. polyphemus were obtained from Pleasant Bay in Chatham, MA and housed at the

145 Marine Resources Center (MRC) of the Marine Biological Laboratory in Woods Hole, MA during

146 August-September, 2009. Animal collections were approved by the Commonwealth of Massachusetts 
147 Division of Marine Fisheries, Scientific Permit \#152087. The animals were housed together in flow-

148 through holding tanks with sea water from the Great Harbor, Falmouth, Massachusetts. Water

149 temperature, conductivity, salinity, dissolved oxygen, $\mathrm{pH}$, unionized ammonia, nitrate, and nitrite were

150 measured. The following values were obtained: water temperature, $20.5-21.6^{\circ} \mathrm{C}$; conductivity, 46.81 ;

151 salinity, 32.9-33 ppt; dissolved oxygen, 11.19; pH, 8.02; unionized ammonia, 0 mg/L; nitrite, $0.002 \mathrm{mg} / \mathrm{L}$;

152 nitrate, $4.1 \mathrm{mg} / \mathrm{L}$. Capelin (Mallotus villosus) was fed once weekly. After being acclimated in a $1500 \mathrm{~L}$

153 fiberglass tank for 45 days, 17 female L. polyphemus (weight, 540-800 g; maximum carapace width, 16.5-

$15419 \mathrm{~cm}$ ) were arbitrarily selected from the group to be used in the study: 14 experimental subjects and 3

155 control subjects. Sex determination was based on pedipalp morphology. During selection, the criteria for

156 exclusion included showing evidence of injury (i.e. cracked carapace or missing legs) or any observable

157 external epibionts. Prior to suture placement, an identification indicator was placed (either by application

158 of one or two colored rubber bands secured to the middle of the telson or a number assignment marked

159 centrally on the carapace with a Sharpie ${ }^{\circledR}$ marker). There was no IACUC review for this study as NCSU

160 IACUC has never required review of the use of invertebrates in research or teaching and it is not required

161 by the Animal Welfare Act, Public Health Service Policy, or NCSU policies. However, measures were

162 taken to try to reduce pain and stress while optimizing data collection.

Suture Placement. Horseshoe crabs were held in dorsal recumbency and the surgery site (ventral

telson ligament) was flushed with sterile saline. The soft cuticle was chosen over the hard cuticle

(chitinous exoskeleton) as it would likely have greater knot security and suture placement would more

likely be indicated in less or non-chitinous tissues. The ventral telson ligament was chosen specifically

167 based on ease of access to this area. Two simple interrupted sutures were placed, one to the left and one to

168 the right of midline, using one of five suture types in the ventral aspect of the telson ligament (Fig. 1).

169 Sutures were placed to avoid the carapacial margins, which simplified biopsy procedures later. Suture

170 position was rotated among animals so that each suture material was used twice at both sites, $\mathrm{n}=4$ for

171 each suture type. Tested suture materials included monofilament nylon (Polyamide, Grams, Millersville, 
172 MD), braided silk (Sofsilk, Ethicon, Summerville, NJ), monofilament poly glycolide-e-caprolactone

173 (Monofyl, Oasis Medical, Mettawa, IL), 3-0 polydioxanone (PDS II, Ethicon, Summerville, NJ), and

174 polyglycolic acid (Webcryl, Webster, Sterling, MA). The three control animals had no sutures placed.

175 The same surgeon (AEK) performed all suture placement procedures. Immediately after suture placement,

176 the horseshoe crabs were transferred to one of two $300 \mathrm{~L}$ fiberglass holding tanks and monitored daily for

177 behavior, suture loss, and gross evidence of inflammation or dehiscence at the suture sight.

178

179

180

181

182

183

184

185

186

187

188

189

190

191

192

193

194

195

196

Anesthesia/Euthanasia Protocol. Prior to biopsy collection, local anesthesia with clove oil (2-

Methoxy-4-(2-propenyl)phenol, 4-Allyl-2-methoxyphenol, 4-Allylguaiaco, Eugenol, Sigma-Aldrich, St. Louis, MO ) was to be administered to all subjects topically with a soaked cotton-tipped applicator to saturate the site (Roxanna Smolowitz and AH pers. obs.). Topical clove oil was applied prior to biopsy for the three control subjects who received no further anesthesia. However, the first biopsy from an experimental subject was associated with uncontrollable hemolymph loss. Thus, systemic injection of clove oil was administered to this subject and prior to biopsy collection in the subsequent thirteen subjects in the experimental group. Two $\mathrm{ml}$ of clove oil were injected through the arthrodial membrane of each subject in the experimental group into the cardiac sinus. Higher doses (up to $4 \mathrm{ml}$ ) were administered when needed for immobilization and unresponsiveness of the animal. Time to unresponsiveness to stimuli and suppression of spontaneous movement was noted. Once subjects were unresponsive, biopsy samples were collected. Immediately post-biopsy, experimental group individuals were placed in holding tanks with sea water to facilitate potential spontaneous recovery. Heart rate was monitored via Doppler (Parks Medical Electronics, Aloha, OR) before, immediately after, and a few hours after injection of clove oil in two of the experimental subjects. Doppler readings were taken through the carapace.

Tissue Sample Collection. At 6 days following suture placement, half of the experimental group was removed from their holding tanks for biopsy of the suture sites. Biopsies were taken after euthanasia of all animals in the experimental group except for the first experimental subject undergoing sample collection where biopsies were taken before euthanasia. In the three control subjects, a single biopsy was 
197 collected from each subject with local anesthesia only. These biopsies were taken from the same sites as

198 suture placement in the experimental group. Excisional biopsies were performed using Metzenbaum

199 scissors; a 3-5 mm diameter tissue sample was obtained by one of two surgeons (AEK or AH) for the

200 control and experimental groups. Control subjects were returned to their holding tanks and the biopsy

201 sites were left to heal by second intention (normal long-term integument healing). After sample

202 collection, biopsies were immediately placed in individual cassettes in 10\% neutral buffered formalin.

203 This biopsy procedure was repeated in the remaining half of the experimental group on day 12. Previous

204 suture studies have used similar time frames for gross and histological evaluation, i.e. 6 and 12 days for

205 Aplysia (Anderson et al., 2010) and 7 and 14 days for Xenopus, Caretta, and Cyprinus (Hurty et al., 2002;

206 Govett et al., 2004; Tuttle et al., 2006).

207

The biopsies were processed routinely by the NCSU CVM Histology Laboratory, embedded in

paraffin, sectioned at $5 \mu \mathrm{m}$, and stained with hematoxylin and eosin (HE) for evaluation by light

microscopy. Multiple sections of each biopsy were evaluated by a single board certified (ACVP)

210

pathologist (JML). There is only one known published description of the normal histology of the telson

211

ligament (Fahrenbach, 1999) and this text is currently out of print. Thus, the pathologist was unblinded to

212 the controls to further characterize the normal histology of the microscopic tissue structure in this area.

213 The pathologist created a five point scale based on our previously used grading scheme for suture reaction

214 studies to describe the microscopic changes in the experimental group (Hurty et al., 2002; Govett et al.,

215 2004; Tuttle et al., 2006; Anderson et al., 2010). Each of the biopsy samples were graded for the amount

216 of inflammation and coagulum formation based on the degree of hemocyte infiltration (Table 1). Once the

217 control subjects were healed, they were returned to the wild.

Statistical analysis. Summary statistics and frequency counts were calculated for all variables 
221 12) separately. P-values less than 0.05 were considered to be statistically significant. All analyses were

222 performed in SAS, Version 9.4 (Cary, NC).

223

224

225

226

227

228

229

230

231

232

233

234

235

236

237

238

239

240

241

242

243

\section{Results}

Anesthesia/Euthanasia. Biopsies were collected with local anesthesia for the three control subjects. These subjects had minimal hemolymph loss during biopsy collection. Prior to systemic clove oil injection in the experimental group subjects, heart rate was measured in two of these subjects. Heart rates were $8 \mathrm{bpm}$ and $30 \mathrm{bpm}$. The $30 \mathrm{bpm}$ subject was very active and the $8 \mathrm{bpm}$ subject was quiet. Immediately after the subjects received $2 \mathrm{ml}$ of clove oil, no further heartbeats were detected which was confirmed several hours later. Gill movement and slight reflex action in the claws were noted after cessation of cardiac activity was confirmed by Doppler.

Time from systemic injection of clove oil to lack of response to stimuli, cessation of righting reflex, and suppression of spontaneous movement of the claws and gill movement generally ranged from 2-5 minutes for all subjects in the experimental group. Three subjects had prolonged gill and limb movements and required higher doses of intravascular clove oil; up to $4 \mathrm{~mL}$ were administered. None of the experimental subjects spontaneously recovered after systemic clove oil administration.

Normal histological description of the telson ligament. The non-chitinous telson ligament has variable thickness and is composed of three distinct layers (Fig. 2). The epicuticle- or outermost layer- is thin (approx. 20-40 $\mu \mathrm{m}$ wide in paraffin sections), brightly eosinophilic, and acellular; it appears to have regularly spaced The endocuticle- or middle layer- is pale, lightly eosinophilic, acellular, and much thicker than the epicuticle; it has a linear/layered appearance in paraffin sections. The epidermis- or deepest layer- is predominantly basophilic and consists of tall columnar epithelial cells with clear apical vacuoles, moderately foamy cytoplasm, and basally located nuclei with dense chromatin and no apparent nucleolus (Fig. 3). Beneath the epidermis lies a network of hemolymph sinuses lined by a matrix of 
244 loosely organized connective tissue septae and interspersed with thin striated muscle fibers (Figs. 2 and $2453)$.

Suture Study. All suture knots were intact at the time of biopsy. There was no macroscopic

247

248

249

250

251

252

253

254

255

256

257

258

259

260

261

262

263

264

265

266

267

268

evidence of edema or inflammation after suture placement at the suture sites at 6 or 12 days for any suture type. For each suture material, severity scores varied moderately. Reaction scores did not differ significantly between 6 and 12 days or between suture types, but all suture types elicited tissue reactions when compared to the controls (Table 2). Monofilament nylon (Fig. 3) had the lowest mean (1.3) and range (0-2) for histology scores while polyglycolic acid (Fig. 4) had the highest mean (2.3) and range (04) for histology scores. No changes were appreciated in the epicuticle or endocuticle, but variable amounts of tissue reaction were seen within the epidermis and hemolymph sinuses. If there were no identifiable microscopic changes, the sample was given a Grade 0 (Fig. 3). Histologic samples representing minimal tissue reaction had one to a few scattered, small aggregates of hemocytes infiltrating the epidermis (Grade 1). Mild reactions (Grade 2, Fig. 4) showed more numerous hemocytes than Grade 1, but these aggregates were loosely arranged and spread out. Figure 4 shows polyglycolic acid at 12 days post-suturing; an area of paucicellular hemolymph coagulum is flanked by loose aggregates of granular and agranular (spent) hemocytes in layers. In the healing wound, flattened agranular hemocytes begin to line up in parallel layers (Bursey, 1977), reminiscent of granulation tissue seen in mammalian wound healing. Moderate tissue reactions (Grade 3) showed more intense aggregates of infiltrating hemocytes and severe tissue reactions (Grade 4) showed even more intense, diffuse aggregates of granular and agranular hemocytes with obvious coagulum formation and a very compact cellularity (Fig. 5). In these cases, numerous hemocytes have lost their granules, often creating "halo cells" (Bursey, 1977) with a perinuclear cytoplasmic clear zone.

\section{Discussion}

Unlike in other invertebrate suture studies (e.g. Aplysia, Lumbricus), none of the suture types dehisced prior to sample collection (Anderson et al., 2010; Salgado et al., 2014). Lumbricus were 
269 evaluated at 3 and 6 days post suture application and Aplysia were evaluated at 6 and 12 days post suture

270 application. In Limulus, while there were variable amounts of tissue reaction in the epidermis, there were

271 no appreciable changes to the epicuticle or endocuticle after suture placement in this study. The stability

272 of the dorsal two layers (particularly the endocuticle) could provide knot security and may account for the

273 lack of observable gross changes identified after suture placement.

The lack of cellularity and hemolymph sinuses in the dorsal two layers may also account for the

lack of observable gross changes identified after suture placement. Minimal gross changes were also seen

after suture placement in Aplysia (Anderson et al, 2010). While inflammation and epidermal changes

277

including necrosis were noted grossly in Lumbricus, the tissues lacked the edema that characterizes

however, reports of gross changes noted in the hard and soft cuticle secondary to infectious diseases, infections (Braverman et al., 2012). 
294 repeatable in the telson ligament as well as to determine the recommended suture material in other low or

295 non-chitinous containing tissues. One technical challenge that occurred in our present study is that,

296 despite adequate fixation in 10\% neutral buffered formalin and paraffin embedding, some sections had

297 separation of the epi- and endocuticle layers from the epidermis and/or fragmentation of the sub-cuticular

298 tissues, creating artifactual clear spaces (as in Fig. 5). Nonetheless, we were still able to assess and score

299 the suture reactions in the biopsies. In future studies, alternate fixatives and/or embedding in plastic resin

300 such as glycol methacrylate may provide better tissue stability for sectioning and scoring.

301 Wound healing of the horseshoe crab skeleton differs from that of crustaceans and other

302 invertebrates (Bursey, 1977). There appear to be four phases described by Bursey (1977): 1) lag period, 2)

303 amebocyte (hemocyte) infiltration, 3) hyalinization, and 4) cuticle regeneration. It is likely that a similar

304 process, without the chitinous cuticle formation, occurs in the arthrodial membrane and telson ligament.

305 Hemocyte infiltration and coagulum formation were the most prominent features of wound repair

306 observed in this study. Telson regeneration has been also been described (Clare et al., 1990).

307 Local anesthesia was insufficient for biopsy collection in the experimental subjects due to

308 hemolymph loss. This finding had also been noted in an unpublished pilot study on horseshoe crabs for

309 biopsy collection post suture placement in the telson ligament performed by AH prior to this study. Local

310 anesthesia was sufficient, however, for biopsy collection of the control subjects where no suture had been

311 placed. The increased hemolymph loss in experimental subjects as compared to control subjects may be

312 related to previous migration of hemocytes and a higher hemocyte density in response to suture

313 placement. The infiltration of hemocytes for an extended period of time in response to injury has also

314 been noted in a previous study on horseshoe crabs (Bursey, 1977). This may have implications in

315 appropriate anesthetic procedures and hemostasis during surgery or biopsy collection of horseshoe crabs

316 with diseased or injured tissues. 
319 measured at $8 \mathrm{bpm}$ and $30 \mathrm{bpm}$. The $30 \mathrm{bpm}$ subject was very active and the $8 \mathrm{bpm}$ subject was quiet.

320 Previous studies have shown the effects of water temperature, acute hypoxia, and air exposure on heart

321 rates of Limulus (Redmond et al., 1982). The temperature coefficient was within the normal range but

322 bradycardia was seen with acute hypoxia and with air exposure, with a mean reduction of $37.6 \%$ in heart

323 rate and a decreased blood pressure noted with air exposure. While baseline heart rates and blood

324 pressures were not measured in this study, the lower than normal heart rate measurements in the two

325 subjects monitored are consistent with the individual subject's activity level and with exposure to air.

326 Horseshoe crabs' adaptability to prolonged air exposure likely spans from their annual migration to

327 spawning sites during the mating season. There are no known studies of the effects of air exposure during

328 anesthesia or sedation or with handling stress on the heart rate or blood pressure of horseshoe crabs.

329 Further studies are recommended to determine these effects which can have implications in anesthetic

330 monitoring and safety and other aspects of veterinary care.

Per American Veterinary Medical Association (AVMA) euthanasia guidelines (Leary et al., 2013), clinicians or researchers must choose a method of euthanasia that is rapid, easy to administer, painless, effective, safe, and readily available. Recommendations for euthanasia methods specific to aquatic invertebrates include both physical and chemical methods. Physical methods (i.e. whole body crushing) require pre-anesthesia and many of the chemical methods (i.e. $\mathrm{KCl}$, xylazine, or ketamine injection into the hemolymph sinus) are either controversial or expensive (Leary et al., 2013). Published recommendations for euthanasia specific to horseshoe crabs include pentobarbital injection (390 mg, 1-2 $\mathrm{ml} /$ animal) into the cardiac sinus or destruction of the dorsal ganglion located on the dorsal midline between the eyes (Smith, 2012). Success of the dorsal ganglion method is very dependent on proper user technique and time to death after crushing is unknown. Respiratory, cardiac, and cerebral arrest occurs within 30 seconds after pentobarbital injection (Smith, 2012), but the controlled drug is not always readily 342 available. 

anesthetic by humans for centuries and, more recently, used for invertebrate, amphibian and fish general anesthesia (Gardner, 1997; Treves-Brown, 2000; Goulet et al., 2010; Yingdong et al., 2018). Clove oil immersion baths are effective for fish euthanasia (Noga, 2010) and euthanasia of the American giant crab,

347 Pseudocarcinus gigas, but the latter may require over 25 minutes (Gardner, 1997). Dose- and body

348 weight-dependent histological changes were noted in the African clawed frog, Xenopus laevis, including

349 renal tubular damage and hepatic necrosis, following clove oil immersion for anesthesia (Goulet et al.,

350 2011) and cutaneous necrosis was noted in Xenopus after topical application with a Eugenol-soaked gauze

351 (Ross et al., 2006). High concentrations of clove oil are also irritating to human skin (Noga, 2010). As a

352 known hepatotoxin, clove oil may be a safety concern for the handler when used as an immersion versus

353 an injection. There were no identified local histopathology effects of topically administered clove oil

354 noted in the telson ligament in this study, but the degree of systemic absorption and other tissue sites were

355 not evaluated. While there are no known studies of the effects of clove oil in aquatic invertebrate

356 hematology, biochemistry, or histopathology, these effects were studied in the common carp, Cyprinus

357 carpio (Velisek et al., 2005). There were no effects on hematologic parameters, but reversible

358 biochemical changes (transient hyperglycemia and increased inorganic phosphates) and histopathology

359 changes (capillary ectasia of the gill filaments) were noted shortly after clove oil immersion although

360 these changes resolved after 24 hours. Further research is recommended to evaluate the effects of topical

361 clove oil application, systemic administration of clove oil into the cardiac sinus, and immersion in clove

362 oil baths for sedation, anesthesia and euthanasia on horseshoe crab hemocytes, blood chemistries,

363 biological parameters (i.e. heart rate and blood pressure), and chitin and non-chitin containing tissues. It

364 is also recommended to further evaluate the effectiveness of clove oil for local and systemic anesthesia.

365 The findings in this study suggest that intracardiac injections of clove oil (2-4 $\mathrm{ml} / \mathrm{kg}) \mathrm{can} \mathrm{be} \mathrm{a} \mathrm{humane,}$

366 economical, accessible, and safe alternative to pentobarbital for euthanasia of horseshoe crabs.

\section{Conclusions}


369 polyglycolic acid) were superior with regards to holding in the telson ligament and no

370 dehiscence was observed. Nylon caused the least amount of tissue reaction and would be our

371 recommended first choice for use in a chelicerate in need of soft tissue wound repair. Intracardiac

372 Eugenol at a dose of $2-4 \mathrm{~mL} / \mathrm{kg}$ was determined to be a relatively fast and effective means of horseshoe

373 crab euthanasia.

374

375

376

377

378

379

380

381

382

383

384

385

386

387

388

389

390

391

392

393

394

\section{Acknowledgements}

We thank Kent Passingham for logistical assistance and Roxanna Smolowitz for her input on euthanasia.

We also thank the NCSU CVM Histology laboratory for their time and assistance with the biopsy samples.

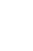

(1)

387

Peer) reviewing PDF | (2018:10:32319:1:2:NEW 23 Apr 2019) 
Anderson ET, Davis AS, Law JM, Lewbart GA, Christian LS, Harms CA. 2010. Gross and histologic 405

406

407

408

409

410

411

412

413

414

415

416

417

418

419

420

421

422

423

424

425

426

427

428

429

430

431

432

433

434 evaluation of five suture materials in the skin and subcutaneous tissue of the California sea hare (Aplysia californica). Journal of the American Association for Laboratory Animal Science, 49(1): 64-68.

Anderson RL, Watson III WH, and CC Chabot. 2013. Sublethal behavioral and physiological effects of the biomedical bleeding process on the American horseshoe crab, Limulus polyphemus. Biological Bulletin, 225(3):137-151.

Atlantic States Marine Fisheries Commission (ASMFC). 2006. Addendum IV to the Fishery Management Plan for Horseshoe Crab. Fishery Management Report No. 32d of the Atlantic States Marine Fisheries Commission. Washington, DC.

Atlantic States Marine Fisheries Commission (ASMFC). 2009. Horseshoe crab stock assessment report. Arlington.

Atlantic States Marine Fisheries Commission (ASMFC). 2010b. Addendum VI to the Fishery Management Plan for Horseshoe Crab. Fishery Management Report No. 32f of the Atlantic States Marine Fisheries Commission. Washington, DC.

Atlantic States Marine Fisheries Commission (ASMFC). 2015. 2015 Review of the Atlantic States Marine Fisheries Commission Fisheries Management Plan for Horseshoe Crab (Limulus polyphemus) 2014 Fishing Year. Washington, DC.

Atlantic States Marine Fisheries Commission (ASMFC). 2017. Horseshoe Crab. Available online at: http://www.asmfc.org/species/horseshoe-crab

Braverman H, Leibovitz L, Lewbart, GA. 2012. Green algal infection of American horseshoe crab (Limulus polyphemus) exoskeletal structures. Journal of Invertebrate Pathology, 111.1: 90-3.

Bursey CR. 1977. Histological response to injury in the horseshoe crab, Limulus polyphemus. Canadian Journal of Zoology, 55:1158-1165.

435 
457

458

459

460

461

462

463

464

465

466

467

468

469

470

471

472

473

474

475

476

477

478

479

480

481

482

483

Clare AS, Lumb G, Clare PA, Costlow JD. 1990. A morphological study of wound repair and telson regeneration in postlarval Limulus polyphemus. Invertebrate Reproductive Development, 17: 77-87.

Eagle, J. 2001. Issues and Approaches in Regulation of the Horseshoe Crab Fishery In: Limulus in the Limelight: A Species 350 Million Years in the Making and in Peril? ed. Tanacredi, J.T. Kluwer Academic/Plenum Publishers, New York, 85-92.

Eldredge, N. 2001. Preserving a Living Fossil. In: Limulus in the Limelight: A Species 350 Million Years in the Making and in Peril? ed. Tanacredi, J.T. Kluwer Academic/Plenum Publishers, New York, 157-160.

Fahrenbach WH. Merostomata. 1999. In: Microscopic Anatomy of Invertebrates. eds. Harrison FW and Locke M. Wiley-Leiss, New York, 8A: 21-115.

Fossum TW. 2007. Small Animal Surgery, $3^{\text {rd }}$ edition. Mosby/Elsevier: St. Louis, Mo.

Gardner C. 1997. Options for immobilization and killing crabs. Journal of Shellfish Research, 16: 219224.

Gore SR, Hadfield CA, Clayton LA, Clews A. 2006. Challenges of managing horseshoe crabs (Limulus polyphemus) in an interactive exhibit. Proceedings of the 31st Eastern Fish HealthWorkshop, 20.

Goulet F, Hélie P, Vachon P. 2010. Eugenol anesthesia in African clawed frogs (Xenopus laevis) of different body weights. Journal American Association of Lab Animal Science, 49: 460-63.

Goulet F, Vachon P, Hélie P. 2011. Evaluation of the Toxicity of Eugenol at Anesthetic Doses in African Clawed Frogs (Xenopus laevis). Toxicologic Pathology, 39.3: 471-477.

Govett PD, Harms CA, Linder KE, Marsh JC, and Wyneken J. 2004. Effect of Four Different Suture Materials on the Surgical Wound Healing of Loggerhead Sea Turtles, Caretta caretta. Journal of Herpetological Medicine and Surgery, 14.4: 6-11.

Grant, D. 2001. Living on Limulus. In: Limulus in the Limelight: A Species 350 Million Years in the Making and in Peril? ed. Tanacredi, J.T. Kluwer Academic/Plenum Publishers, New York, 135-145.

Hata D, Berkson J. 2003. Abundance of horseshoe crabs (Limulus polyphemus) in the Delaware Bay area. Fisheries Bulletin, 101: 933-938.

Hurton L, Berkson, J, Smith S. 2009. The effect of hemolymph extraction volume and handling stress on horseshoe crab mortality. In: Biology and Conservation of Horseshoe Crabs. eds. Tanacredi JT, Botton ML, and DR Smith. Springer-Science, New York, NY, 331-46.

Hurty CA, Brazik DC, Lewbart GA, McHugh Law J, Sakamoto K. 2002. Evaluation of the tissue reactions in the skin and body wall of koi (Cyprinus carpio) to five suture materials. Veterinary Record, 151: 324-328.

Iwanaga S. 2002. The molecular basis of innate immunity in the horseshoe crab. Current Opinion in Immunology, 14: 87-95. 
484

485

486

487

488

489

490

491

492

493

494

495

496

497

498

499

500

501

502

503

504

505

506

507

508

509

510

511

512

513

514

515

516

517

518

519

520

521

522

523

524

525

526

527

528

529
Iwanaga S, Lee BL. 2005. Recent advances in the innate immunity of invertebrate animals. Journal of Biochem Mol Biology, 38: 128-150.

Krisfalusi-Gannon J, Ali W, Dellinger K, Robertson L, Brady TE, Goddard, MKM, Tinker-Kulberg R, Kepley CL, Dellinger AL. 2018. The Role of Horseshoe Crabs in the Biomedical Industry and Recent Trends Impacting Species Sustainability. Frontier Marine Science, 5(185): 1-13.

Kumar V, Roy S, Sahoo AK, Behera BK, Sharma AP. 2015. Horseshoe crab and its medicinal values. International Journal of Current Microbiology and Applied Sciences, 4.2: 956-964.

Leary S, Underwood W, Anthony R, Anthony R, Cartner S, Corey D, Grandin T, Greenacre, C, Gwaltney-Brant S, McCrackin MA, Meyer R, Miller D, Shearer J, Yanong R. 2013. AVMA Guidelines for the euthanasia of animals: 2013 edition. AVMA, Schaumburg Ill.

Loeb L. 1902. On the Blood Lymph Cells and inflammatory Processes of Limulus. The Journal of medical research, 7.1: 145-58.

Lui JS, Passaglia CL. 2009. Using the Horseshoe Crab, Limulus Polyphemus, in Vision Research. Journal of Visualized Experiments, 29: 1384.

Leibovitz L, Lewbart GA. 2004. Diseases and symbionts: Vulnerability despite tough shells. In: The American Horseshoe Crab. eds Shuster CN Jr, Barlow RB, Brockmann HJ. Harvard University Press, Cambridge, 245-275.

Noga E. 2010. Pharmacopoeia. In: Fish Diseases: Diagnosis and Treatment $2^{\text {nd }}$ edition. Wiley-Blackwell, Ames, Iowa, 375-420.

Novitsky TJ, 2001. Biomedical Products from Horseshoe Crabs. In: Limulus in the Limelight: A Species 350 Million Years in the Making and in Peril? ed. Tanacredi, J.T. Kluwer Academic/Plenum Publishers, New York, 79-84.

Novitsky TJ. 2009. Biomedical applications of Limulus Amebocyte Lysate. In: Biology and Conservation of Horseshoe Crabs. eds. Tanacredi JT, Botton ML, Smith D Springer Science+Business Media, LLC; New York, NY, 315-329.

Nolan MW, Smith SA. 2009. Clinical Evaluation, Common Diseases, and Veterinary Care of the Horseshoe Crab, Limulus polyphemus. In: Biology and Conservation of Horseshoe Crabs. eds. Tanacredi JT, Botton ML, and DR Smith. Springer Science, New York, NY, 79-99.

Packard AS.1880a. The anatomy, histology, and embryology of Limulus polyphemus. Memoirs of the Boston Society of Natural History, 1-45.

Packard AS. 1880b. Structure of the eye of Limulus. American Naturalist, 14:212-213.

Redmond JR, Jorgensen DD, Bourne GB. 1982. Circulatory physiology of Limulus. In: Physiology and Biology of Horseshoe Crabs. eds. Bonaventura J, Bonaventura C, S Tesh. Alan R. Liss, Inc, New York, 133-146.

Peer] reviewing PDF | (2018:10:32319:1:2:NEW 23 Apr 2019) 
530

531

532

533

534

535

536

537

538

539

540

541

542

543

544

545

546

547

548

549

550

551

552

553

554

555

556

557

558

559

560

561

562

563

564

565

566

567

568

569

570

571

572

573

574

575

576

Ross A., Guenette SA, Helie P, Vachon P. 2006. Case of cutaneous necrosis in African clawed frogs Xenopus laevis after the topical application of eugenol. Can Vet Journal, 47: 1115-17.

Salgado MA, Lewbart GA, Christian LS, Griffith EH, Law JM. 2014. Evaluation of five different suture materials in the skin of the earthworm (Lumbricus terrestris). SpringerPlus, 3:423.

Smith DR, Brockmann HJ, Beekey MA, King TL, Millard MJ, Zaldivar-Rae J. 2017. Conservation Status of the American Horseshoe Crab, (Limulus polyphemus): a regional assessment. Rev Fish Biology Fisheries, 27: 135-75.

Smith SA, Berkson JM, Barratt RA. 2002. Horseshoe crab (Limulus polyphemus) hemolymph, biochemical and immunological parameters. Proceedings of the International Association for Aquatic Animal Medicine, 33:101-102.

Smith SA. 2012. Horseshoe Crabs. In: Invertebrate Medicine, $2^{\text {nd }}$. ed Lewbart, GA. Wiley-Blackwell Publisher: Ames, IA, 177-184.

Smith SA, Berkson J. 2005. Laboratory culture and maintenance of the horseshoe crab (Limulus polyphemus). Laboratory Animal, 34(7): 27-34.

Tanacredi, JT, 2001. Horseshoe Crabs Imperiled?. In: Limulus in the Limelight: A Species 350 Million Years in the Making and in Peril? ed. Tanacredi, J.T. Kluwer Academic/Plenum Publishers, New York, 157-160.

Treves-Brown KM. 2000. Applied Fish Pharmacology. Dodrecht, The Netherlands: Kluwer Academic Publishers.

Tuttle AD, Law JM, Harms CA, Lewbart GA, Harvey SB. 2002. Evaluation of the gross and histological reactions to five commonly used suture materials in the skin of the African clawed frog (Xenopus laevis). Journal of the American Association of Laboratory Animal Science, 45(6): 22-26.

Tuxbury KA, Shaw GC, Montali RJ, Clayton LA, Kwiatkowski NP, Dykstra MJ, Mankowski JL. 2014. Fusarium solani species complex associated with carapace lesions and branchitis in captive American horseshoe crabs Limulus polyphemus. Diseases of Aquatic Organisms, 109: 223-230.

Velisek J, Svobodova Z, Piackova V, Groch L, Nepejchalova, L. 2005. Effects of clove oil anesthesia on common carp (Cyprinus carpio L). Vet. Med.-Czech, 50.6: 269-275.

Walls BA, Berkson JM. 2003. Effects of blood extraction on horseshoe crabs (Limulus polyphemus). Fisheries Bulletin, 101:457-459.

Yingdong L, Qiuxin S, Zhibin H, Na S, Xu L, Xiadong L. 2018. Anaesthetic effects of eugenol on grass shrimp (Palaemonetes sinensis) of different sizes at different concentrations and temperatures. Scientific Reports, 8.

Peer) reviewing PDF | (2018:10:32319:1:2:NEW 23 Apr 2019) 
577

578

579

580

581

582

583

584

585

586

587

588

589

590

591

592

593

594

595

596

597

598

599

600

601

602

603

604

605

606

607

608

609

610

611

612

Figure Legends:

Figure 1. Suture placement (close-up) in the telson ligament of an adult horseshoe crab

(Limulus polyphemus).

Figure 2. Normal histology of the three-layered telson ligament of the horseshoe crab (Limulus

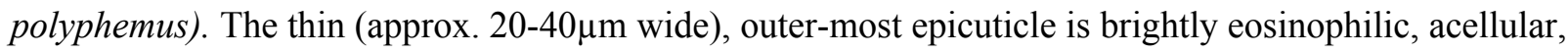
and has regularly spaced, concave indentations or notches approx. $200-400 \mu \mathrm{m}$ deep. The endocuticle is the middle layer, is also acellular, and has a pale eosinophilic, finely layered appearance in hematoxylin and eosin-stained (HE) paraffin sections. The epidermis (see also Fig. 3) is basophilic and is composed of tall columnar cells with basally-located nuclei. HE staining; bar $=200 \mu \mathrm{m}$.

Figure 3. High mag. (40X objective), section of telson ligament that was sutured with monofilament nylon, 6 days post-suturing, scored as grade 0 (no remarkable microscopic changes). The tall columnar cells of the epidermis (E) have clear apical vacuoles, moderately foamy cytoplasm, and basally located nuclei with dense chromatin and no apparent nucleolus. Below the epidermis are the hemolymph sinuses (S) lined by fine fibrocyte septae and interspersed with small clusters of skeletal muscle fibers (M). HE; bar $=20 \mu \mathrm{m}$.

Figure 4. Polyglycolic acid (Webcryl), grade 2 suture reaction, 12 days post-suturing. At bottom center, the healing wound is dominated by a dense, proteinaceous hemolymph coagulum $(\mathrm{C})$ which is paucicellular centrally. This is flanked by moderate infiltrates of granular and agranular (spent) hemocytes (H). Some agranular hemocytes (arrowheads) are elongated with flattened/ovoid nuclei and, in the outer layers, are arranged roughly parallel to each other. The overlying epidermis shows no remarkable abnormalities at this stage of healing. HE; bar $=50 \mu \mathrm{m}$.

Figure 5. Polydioxanone (PDS II), grade 4 suture reaction, 6 days post-suturing. This high mag. photo shows robust infiltrates of granular (G) and agranular (arrowheads) hemocytes distributed throughout the hemolymph coagulum. Some agranular hemocytes (arrowheads) have angular to stellate to flattened/ovoid nuclei. This photo also illustrates a technical challenge encountered in sectioning some of the telson ligaments, with separation artifact (A) of the endo- and epicuticle layers from the epidermis as well as fragmentation $(\mathrm{F})$ of the coagulum. HE; bar $=20 \mu \mathrm{m}$. 


\section{Figure 1}

Suture placement in the horseshoe crab telson membrane.

Suture placement (close-up) in the telson membrane of an adult horseshoe crab (Limulus polyphemus).

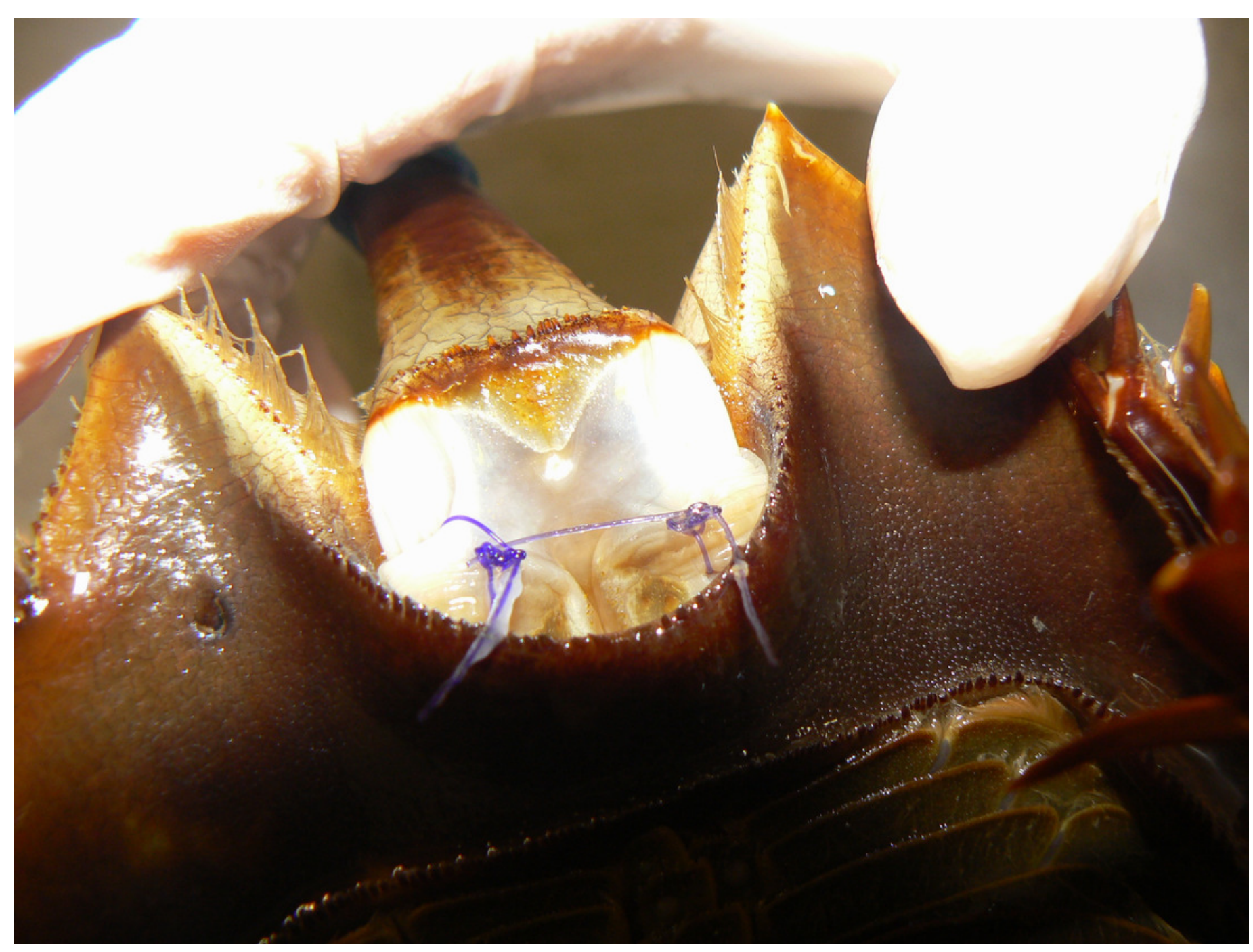




\section{Figure 2 (on next page)}

This figure illustrates normal telson membrane histology.

Normal histology of the telson membrane of the horseshoe crab (Limulus polyphemus) with three distinct layers. 


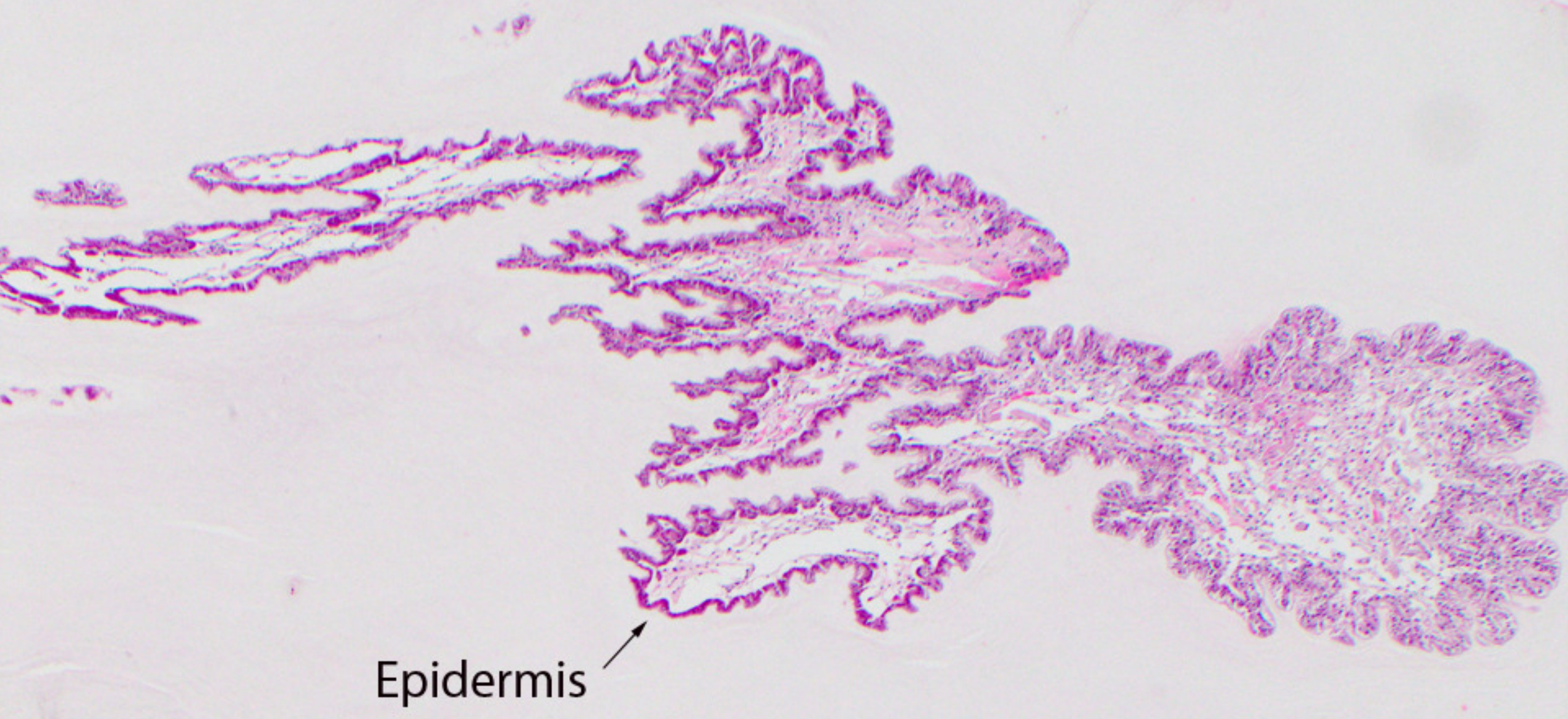

\section{Endocuticle}

\section{Epicuticle}


Figure 3 (on next page)

This micrograph illustrates normal telson membrane anatomy with a close view of the outer two layers.

Normal histology of the telson membrane of the horseshoe crab (Limulus polyphemus) with three distinct layers (close up of outer two layers). 


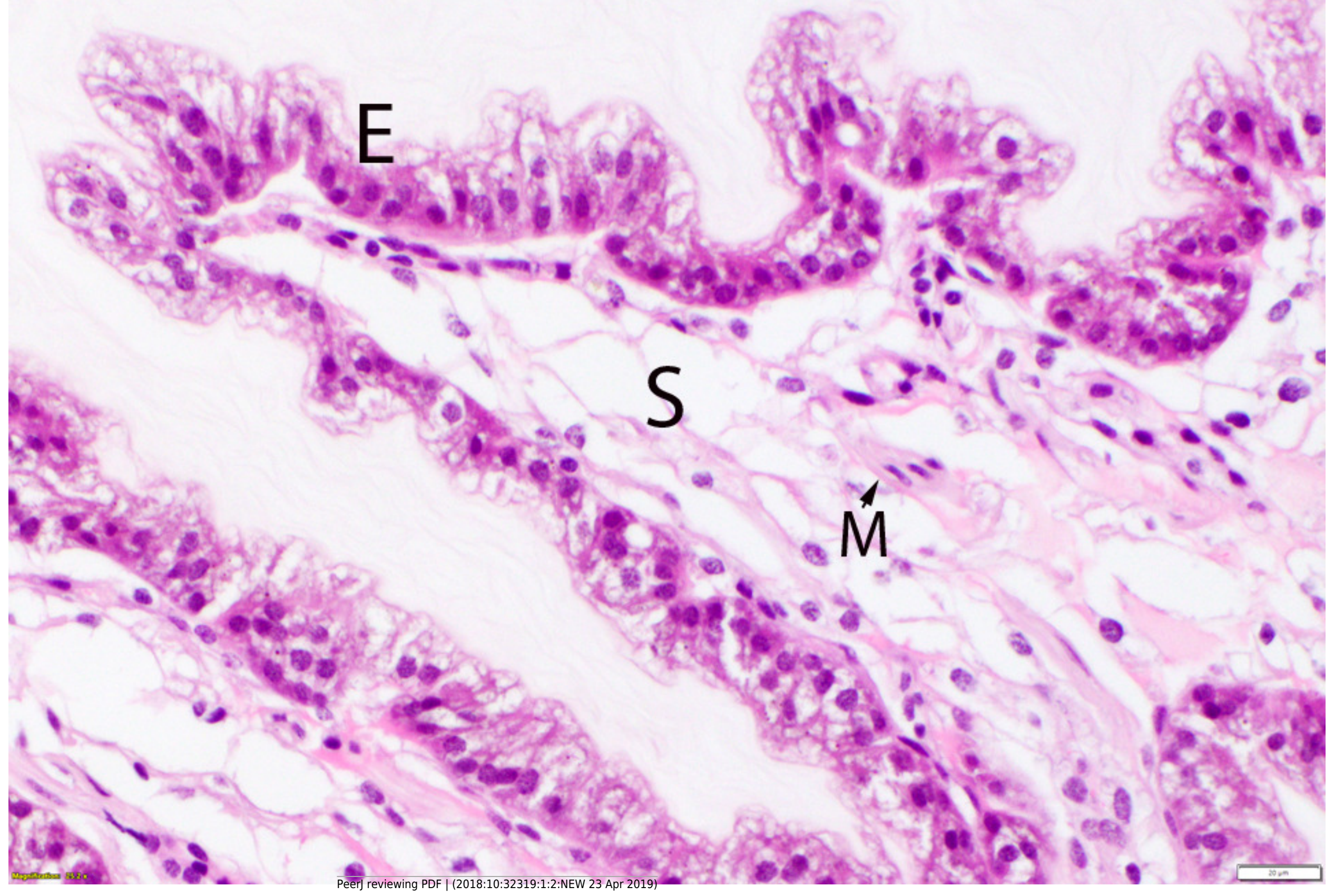


Figure 4 (on next page)

This image shows a grade 0 reaction (essentially, no inflammation).

Grade 0 suture reaction with no remarkable microscopic changes. Top center are normal skeletal muscle fibers (SM). Below center and left is loose connective tissue (CT). At right is normal columnar epithelium (CE) with basilar located nuclei. 


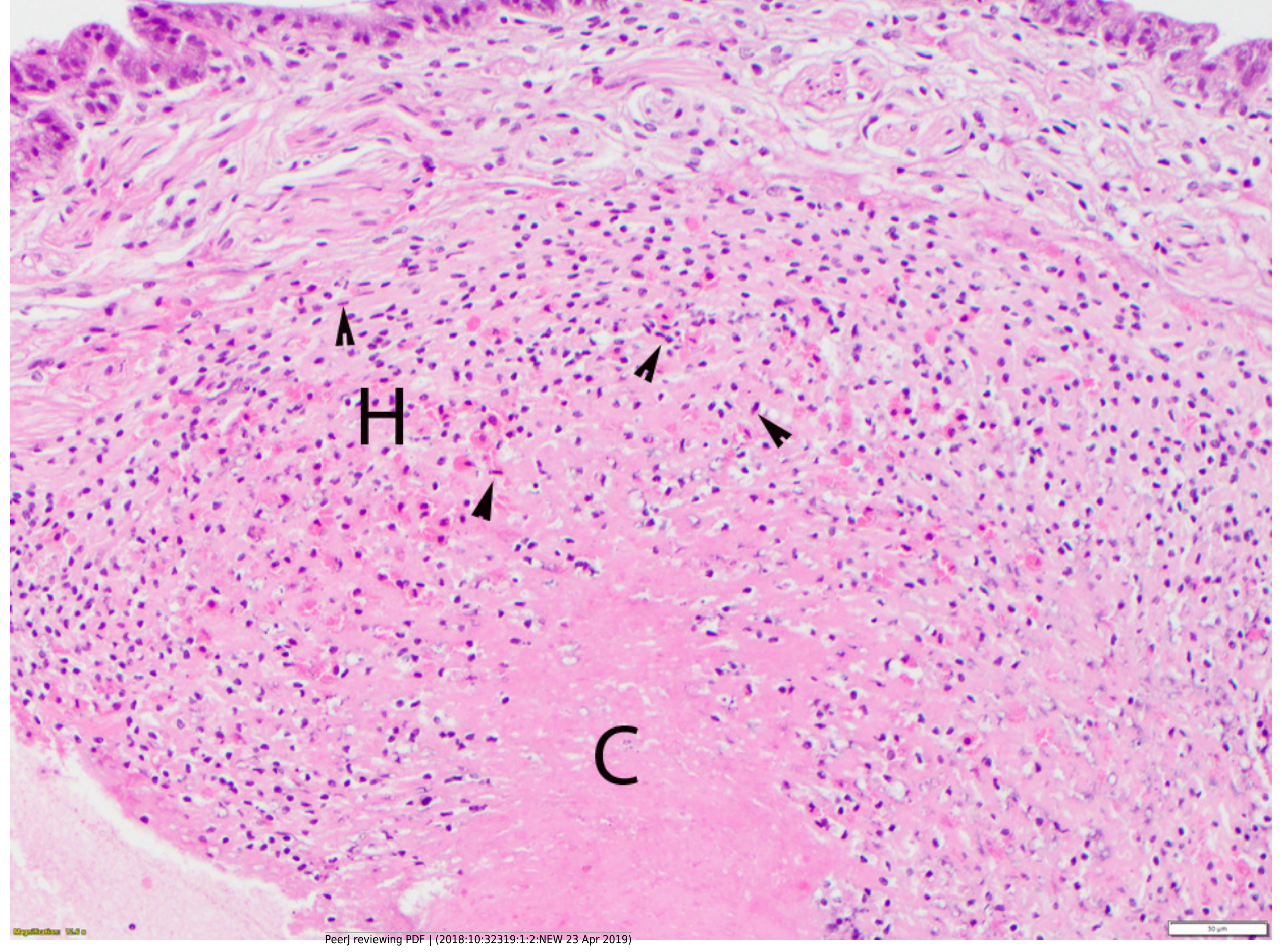


Figure $\mathbf{5}$ (on next page)

This micrograph illustrates a grade 2 suture reaction to Webcryl, a synthetic suture material.

Grade 2 suture reaction (polyglycolic acid, Webcryl, Webster, Sterling, MA). In the center are focal infiltrates of eosinophilic granular amebocytes (A). The surrounding epithelium is mildly hypertrophied. There is moderate tissue artifact with separation in this specimen. 
Manuscript to be reviewed

$\because x$

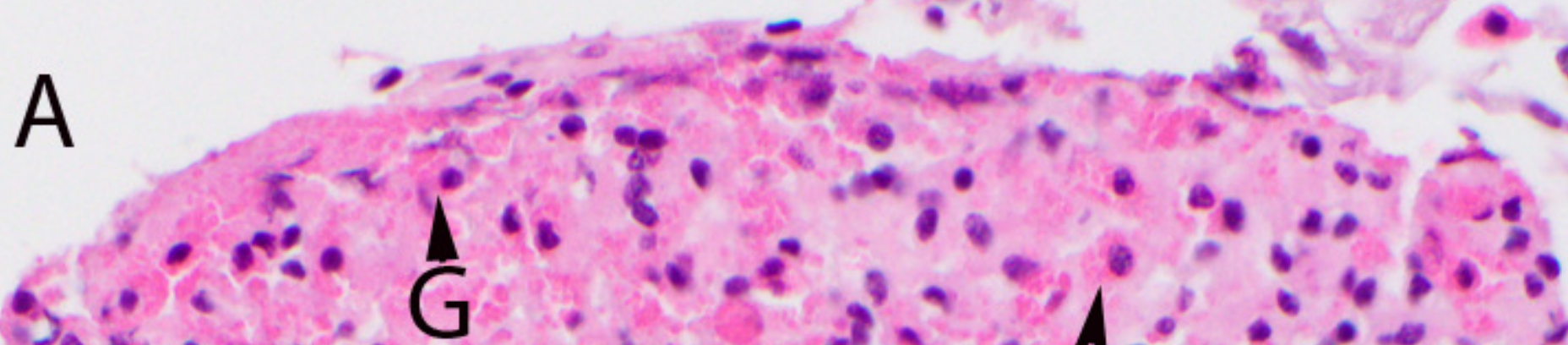

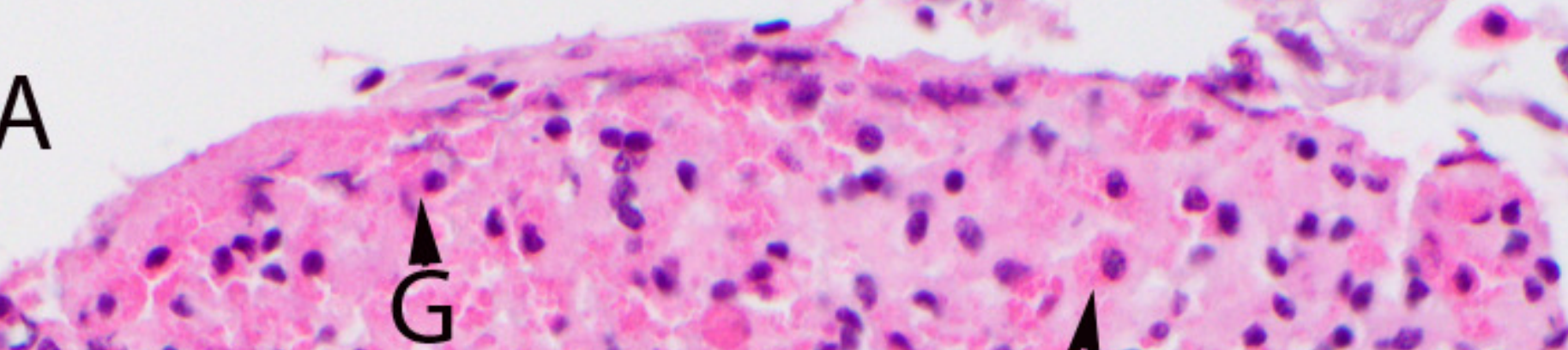

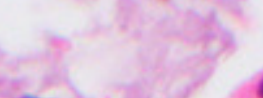

A 8,6

3.,

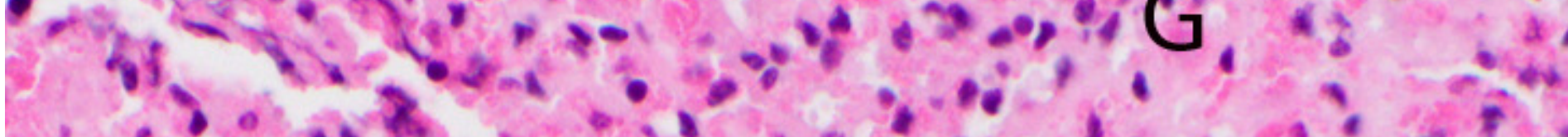

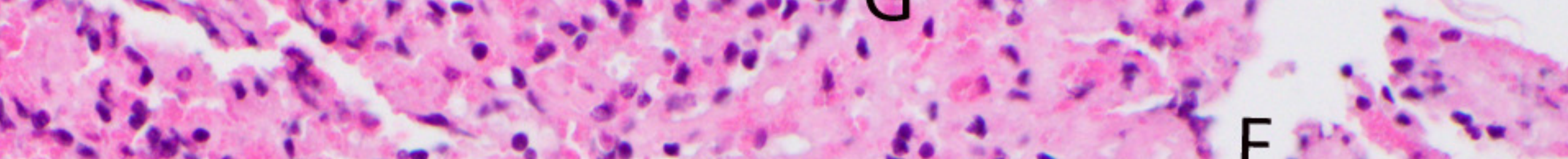

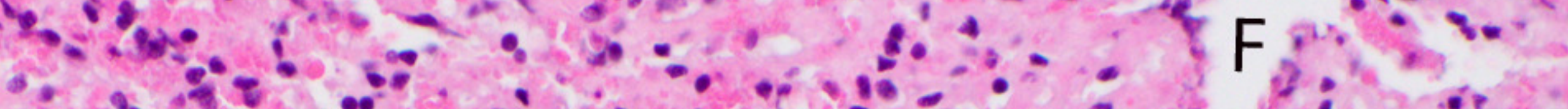

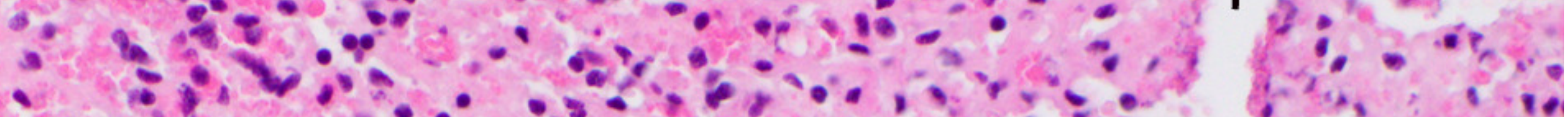

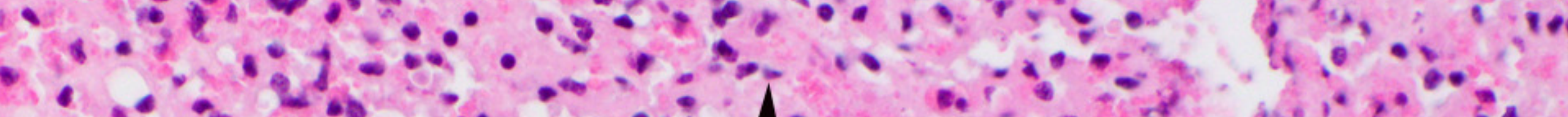

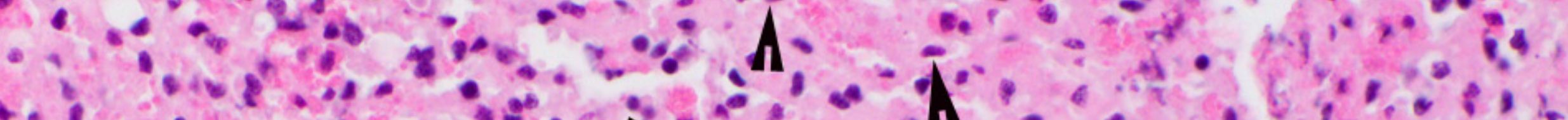

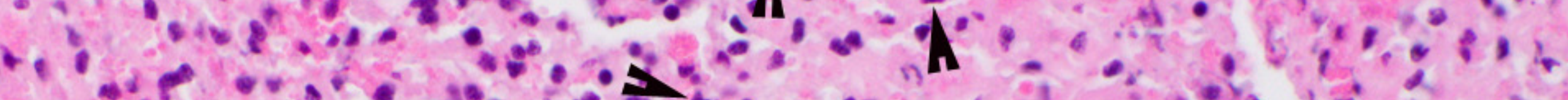

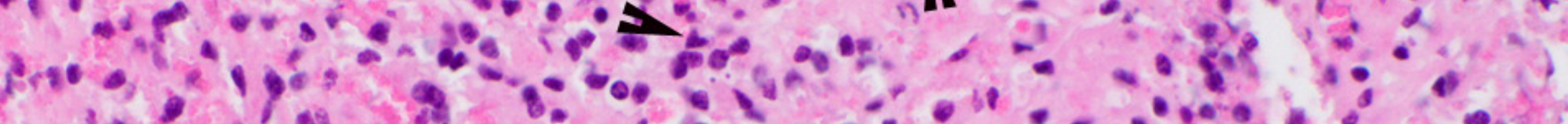

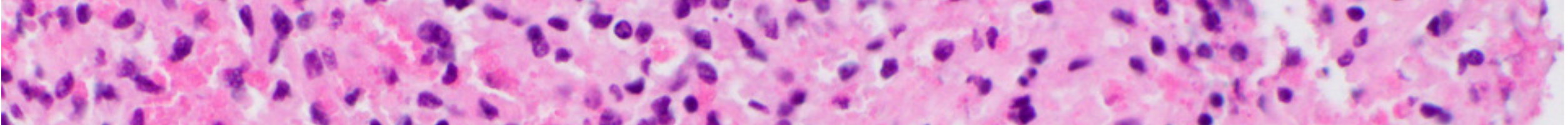

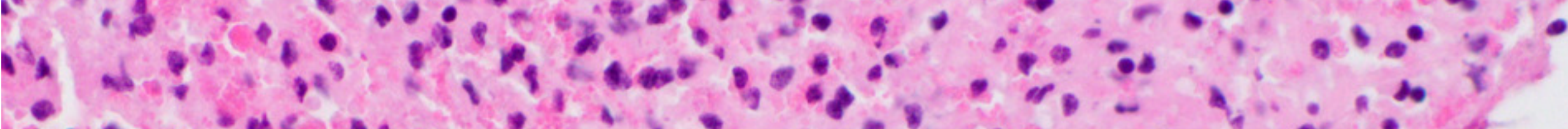

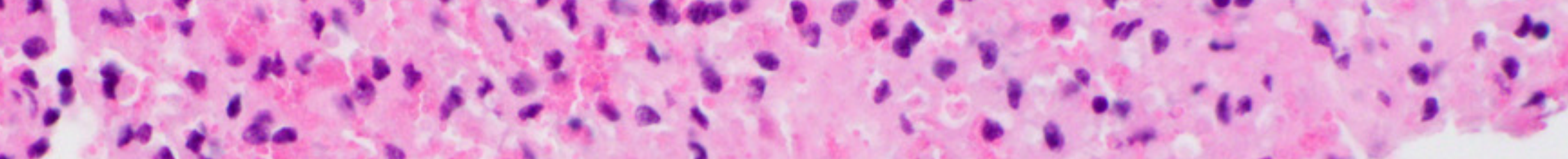

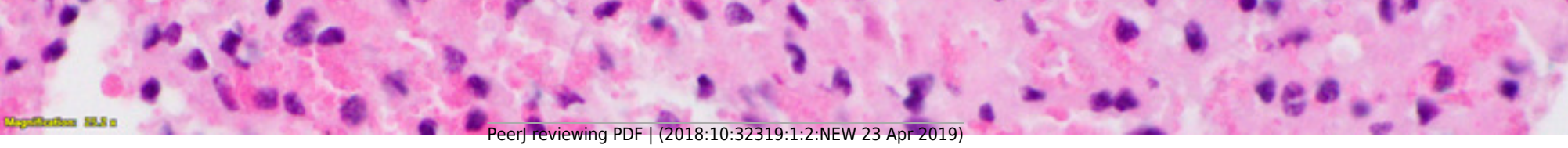




\section{Table $\mathbf{1}$ (on next page)}

This table defines the five-point scale used to grade suture reactions.

Five-point scale for degree of suture reaction of biopsy samples. 
1 Table 1. 5-point scale for degree of suture reaction of biopsy samples collected 6 and 12 days post suture

2 placement in the telson ligament in Limulus polyphemus, $\mathrm{n}=14$

\begin{tabular}{|c|c|}
\hline Score & Descriptions \\
\hline 0 & $\begin{array}{l}\text { No identifiable microscopic changes } \\
\text { or deviations from the non-sutured site }\end{array}$ \\
\hline 1 & $\begin{array}{l}\text { Minimal inflammation: } \\
\text { one to a few scattered, small aggregates of hemocytes infiltrating the epidermis }\end{array}$ \\
\hline 2 & $\begin{array}{l}\text { Mild inflammation: } \\
\text { scattered to more numerous activated and granular hemocytes, but loosely arranged and/or spread } \\
\text { out }\end{array}$ \\
\hline 3 & $\begin{array}{l}\text { Moderate inflammation: } \\
\text { more intense aggregates of infiltrating hemocytes }\end{array}$ \\
\hline 4 & $\begin{array}{l}\text { Severe inflammation: } \\
\text { even more intense, diffuse aggregates of hemocytes with obvious coagulum formation } \\
\text { and a very compact cellularity }\end{array}$ \\
\hline
\end{tabular}

3 


\section{Table 2 (on next page)}

This table contains all of the pertinent data related to inflammations scores to the suture types.

Histology scores based on suture type. 
1 Table 2. Overall histology scores based on suture type placed in the telson ligament of Limulus 2 polyphemus

\begin{tabular}{|c|c|c|}
\hline \multirow{2}{*}{ Suture Type } & \multicolumn{2}{|c|}{ Histology Score } \\
& Mean & $0-2$ \\
\hline Monofilament nylon & 1.3 & $0-4$ \\
\hline Braided silk & 1.3 & $1-2$ \\
\hline Poliglecaprone & 1.5 & $0-4$ \\
\hline Polydioxanone & 2 & $0-4$ \\
\hline Polyglycolic acid & 2.3 & \\
\hline
\end{tabular}

3

4

5

6

7 